\section{"Anything goes"?: o diálogo implícito de Paul Feyerabend com dois pesquisadores brasileiros, Maurício da Rocha e Silva e Newton Freire-Maia}

\author{
"Anything goes"?: the \\ implicit dialogue between \\ Paul Feyerabend and two \\ Brazilian researchers, \\ Maurício da Rocha e Silva \\ and Newton Freire-Maia
}

Francisco Inácio Bastos

Pesquisador do Laboratório de Informações em Saúde/Instituto de Informação Científica e Teconológica em Saúde/Fundação Oswaldo Cruz e do Conselho Nacional de Desenvolvimento Científico e Tecnológico

Av. Brasil, 4.365/229

21040-900 - Rio de Janeiro - RJ - Brasil

Recebido para publicação em dezembro de 2008. Aprovado para publicação em maio de 2009.
BASTOS, Francisco Inácio. "Anything goes?": o diálogo implícito de Paul Feyerabend com dois pesquisadores brasileiros, Maurício da Rocha e Silva e Newton Freire-Maia. História, Ciências, Saúde - Manguinhos. Rio de Janeiro, v.17, n.1, jan.-mar. 2010, p.141-152.

Resumo

O filósofo Paul Feyerabend e os cientistas brasileiros Maurício da Rocha e Silva e Newton Freire-Maia foram contemporâneos e viram-se às voltas com dilemas fundamentais da ciência. A proposta anarquista de Feyerabend, então embrionária, foi formulada em paralelo por Rocha e Silva, em sua crítica ao método científico.

Transcorridas duas décadas, as ideias de Feyerabend parecem motivar implicitamente Newton Freire-Maia nas reflexões sobre a ciência. A teia de inter-relações das ideias desses três homens - que jamais interagiram - toca questões centrais da ciência brasileira de 1960 a 1980, período em que ela se consolida, em diálogo com a nascente reflexão sobre a ciência e o método científico no país.

Palavras-chave: Paul Feyerabend (1924-1994); Maurício da Rocha e Silva (1910-1983); Newton Freire-Maia (1918-2003); filosofia da ciência; biologia.

\section{Abstract}

The philosopher Paul Feyerabend and Brazilian scientists Maurício da Rocha e Silva and Newton Freire-Maia were contemporaries and lived surrounded by the fundamental dilemnas of science. The anarchist proposal of Feyerabend, then embryonic, was formulated in parallel by Rocha e Silva in his criticism of the scientific method. Two decades later, Feyerabend's ideas seemed implicitly to stimulate Newton Freire-Maia in his reflections on science. The web of interrelationships in the ideas of these three men - who never interacted - touches on central issues for Brazilian science from 1960 to 1980, a period in which the latter is consolidated in a dialogue with the nascent reflection on science and the scientific method in Brazil.

Keywords: Paul Feyerabend (1924-1994); Maurício da Rocha e Silva (1910-1983); Newton Freire-Maia (1918-2003); philosophy of science; biology. 
$\mathrm{P}$ aul Karl Feyerabend (1924-1994), filósofo e historiador da ciência, nasceu na Áustria e notabilizou-se como um dos críticos mais ácidos da validade epistemológica de quaisquer estratégias metodológicas abrangentes, propostas pelas mais diversas correntes contemporâneas da filosofia da ciência. Definiu-se, em seus sucessivos livros, a partir de Against method, originalmente publicado em 1975, como um "anarquista da ciência"1, ainda que faça restrições aos desdobramentos do anarquismo, intitulando-se dadaísta numa nota de rodapé (Feyerabend, 1978, p.21). Em sua correspondência com o filósofo da ciência Imre Lakatos (1922-1974), de origem húngara e nome de batismo Imre Avrun Lipschitz, expressou uma visão de mundo em que vida e obra se entrelaçam de forma a reforçar um credo anarquista - ou dadaísta -, que perpassa todos os aspectos da existência e do conhecimento artístico, filosófico e científico (Motterlini, 1999).

Os dois outros personagens mencionados no título deste artigo, até onde nos foi possível averiguar, jamais discutiram ou ao menos citaram a obra de Feyerabend. No caso do farmacologista e fisiologista Maurício Oscar da Rocha e Silva (1910-1983), há evidente falta de sintonia cronológica entre a obra que escreveu sobre o método ou, antes, sua ausência, denominada Lógica da invenção (Rocha e Silva, 1965), e os trabalhos de Feyerabend anteriores a Against method, redigidos primeiro em alemão e depois em inglês, cuja maioria só é acessível em revistas especializadas de filosofia.

Finalmente, a terceira de nossas dramatis personae é o doublé de geneticista e ensaísta Newton Freire-Maia (1918-2003), que, em paralelo a um alentado número de publicações no campo da genética, escreveu alguns volumes em que enfeixou suas reflexões sobre a filosofia e a história da ciência, dos quais destacamos duas obras publicadas em anos recentes: A ciência por dentro, cuja edição original é de 1990, e Verdades da ciência e outras verdades: a visão de um cientista, postumamente publicada em 2008 (Freire-Maia, 2000, 2008). Também sem jamais mencionar de modo explícito a obra de Feyerabend, ao menos na bibliografia a que tive acesso, seu minucioso e bem fundamentado esforço de delimitar o espaço de atuação da ciência e do cientista e de discutir os critérios de consistência e validade em ciência representa, por um lado, reafirmação do método científico ou, antes, dos métodos, como veremos a seguir, e, por outro, crítica a uma ciência que ele constata abastardada por mecanicismo, reducionismo e arrogância perante a outras modalidades do pensamento contemporâneo.

\section{Uma breve abordagem das ideias centrais de Feyerabend}

Para um autointitulado anarquista ou dadaísta, surpreendem a absoluta sistematicidade e a metódica e detalhada exposição de argumentos que norteia o livro que Feyerabend redigiu contra o método, ampliado em duas edições subsequentes, a última datada de 1993, com pós-escrito sobre o significado e o escopo do relativismo em filosofia, além de novos prefácios às edições em inglês e chinês.

Ao longo das reedições da obra, o relativismo ganha maior espaço, com a dissociação progressiva do que um dos autores que se abeberaram em sua obra, o então jovem Bruno Latour (em seu livro publicado em parceria com Steve Woolgar, cuja primeira edição é de 1979, em especial, no sexto capítulo) define como a oposição entre o contexto da justificação 
ou fundamentação e o da descoberta (Latour, Woolgar, 1986). Como discute Feyerabend e Latour (p.251) questiona o citando explicitamente, se a própria vida pode ser compreendida como combinação de acaso e 'remendo' - tradução empobrecedora do termo clássico da biologia evolucionista contemporânea, tinkering, literalmente 'remendo' ou 'trabalho de funileiro' -, por que a ciência teria de escapar a esse caráter circunstancial de construção dos fatos?

Creio ser possível entender essa metódica argumentação antimetodológica como reflexo da formação filosófica e científica do autor, fortemente lastreada na física, mas também como tentativa de minimizar, de antemão, as críticas a sua diatribe devastadora ao método científico. É como se o autor prevenisse seus potenciais críticos: "minha crítica ao método não procede de minha ignorância acerca da história da ciência, nem de minha incapacidade de utilizar a lógica mais estrita no processo de desdobrar minha argumentação". De qualquer modo, soa-me estranho, como leitor, uma desconstrução tão incrivelmente metódica... do método.

A favor de Feyerabend podemos invocar, entretanto, o precedente ilustre de Baruch Spinoza, que virou de cabeça para baixo a filosofia de sua época, ao mover devastadora crítica ao cartesianismo - o cânone lógico-filosófico de então -, além de entrar em conflito com as autoridades religiosas da comunidade judaica de Amsterdã, que acabaram por excomungá-lo, utilizando, entretanto, na empreitada lógica de argumentação que ele próprio denominou "Ordine geometrico demonstrata" (Demonstrada nos moldes da geometria, em tradução livre), expressão que serve de subtítulo a sua Ética. Nesse sentido, ambos Feyerabend e Spinoza - movem uma crítica 'por dentro' aos sistemas que pretendem revolucionar e lançam mão de métodos canônicos de exposição para criticar o cânone. ${ }^{2}$

Em breve explanação da argumentação de Feyerabend em Contra o método, cabe observar que o livro segue argumentação basicamente linear: as sucessivas reformulações dos conceitos científicos são apresentadas sequencialmente, sempre em sua moldura histórica, com linha condutora ancorada na física clássica, seguidas de discussão que procura, invariavelmente, demonstrar que o método canônico não só não teria servido de norte aos desdobramentos conceituais e experimentais efetivamente verificados, como, em inúmeros casos, teria sido estorvo ao livre exercício de uma combinação de raciocínio e intuição, proveniente da combinação do psiquismo do cientista com saberes variados, fossem oriundos de outras ciências, da mitologia ou das artes, como a pintura e a literatura de ficção.

Após desconstruir o papel do método na história da ciência, o autor cunha o famoso refrão "Anything goes", ou seja, por quaisquer caminhos que venhamos a trilhar, por meio dos mais "loucos pensamentos" - na expressão de Max Bergman, que apresentamos a seguir -, fato é que a ciência ou, antes, algo que denominamos 'conhecimento científico', anda. Os anos subsequentes de Feyerabend representam uma espécie de alargamento progressivo - em círculos cada vez mais abrangentes e menos centrados na filosofia da ciência estrito senso - de suas reflexões em busca de um 'adeus à razão' (Farewell to reason foi publicada em 1985), culminando em autobiografia em que o ofício de viver é visto sob a lente, tão cara à linguagem cotidiana do português brasileiro, de 'matar o tempo' (Killing time: the autobiography of Paul Feyerabend). 
Feyerabend torna-se o filósofo peripatético por excelência do mundo contemporâneo, não mais nos moldes de seus predecessores gregos, que caminhavam enquanto debatiam e ensinavam, mas em viagens transcontinentais, percorrendo os mais diversos países, universidades e saberes e participando ativamente das revoltas estudantis da década de 1960 (Motterlini, 1999). Preocupa-se o autor em contestar o cânone das obras em filosofia da ciência e construir uma espécie de anticânone que, em sua opinião, enriqueceria a reflexão - em ciência e de modo geral -, assim como teria caráter pedagógico renovador, pois alargaria o arsenal de referências dos jovens filósofos rompendo as barreiras disciplinares ao incorporar a arte, a magia e outros saberes.

Por mais que discordemos de suas teorias, não resta dúvida de que se trata de pensador original e homem intrigante. Iniciou sua trajetória como oficial do Exército nazista, tendo sido condecorado com a Cruz de Ferro após ser ferido em batalha - ferimentos que lhe causariam dores excruciantes vida afora. Tornou-se guru da contracultura nos anos $1960 \mathrm{e}$ um dos disseminadores de textos não canônicos, que julgava essenciais à formação dos futuros filósofos da ciência - se é que esse conceito fazia algum sentido para Feyerabend à época -, como Malleus maleficarum (Martelo contra as bruxas), tratado sobre bruxaria e caça às bruxas redigido na Idade Média, que foi incluído no Index de obras proibidas pela Igreja católica, serviu aos inquisidores e, posteriormente, ganhou fama em meio aos estudantes de filosofia das décadas de 1970 e $1980 .^{3}$

Questão fundamental nas proposições de Feyerabend é subtrair à filosofia da ciência o direito de balizar a prática científica a partir de critérios universalmente válidos, seja em perspectiva sincrônica (de cada momento histórico) ou diacrônica (a partir de uma visão de conjunto da história da ciência), devolvendo a cada cientista a responsabilidade integral pela formulação de seus experimentos e hipóteses, bem como pela interpretação de seus achados e abrindo, com isso, espaço para a proliferação de saberes, experiências práticas e interpretações alternativas, quando não concorrentes. Sua reflexão, como já assinalado, dá acesso à nova geração de pensadores que, como Bruno Latour, adotam uma perspectiva construtivista da ciência em interação com correntes filosóficas contemporâneas como o pós-estruturalismo francês. Nessa mesma corrente se imbrica ainda a redescoberta, por Thomas Kuhn (que prefacia a edição inglesa), da esquecida obra do médico polonês Ludwig Fleck (1896-1961), especialmente do livro Entstehung und Entwicklung einer wissenschaftlichen Tatsache. Einführung in die Lehre vom Denkstil und Denkkollektiv (em inglês, The genesis and development of a scientific fact), que dialoga criticamente com a ciência biomédica do século XIX e início do $\mathrm{XX}$, em moldes similares à mirada crítica que Feyerabend dirige à dinâmica da descoberta $\mathrm{e}$ formulação de conceitos científicos no âmbito da física e da cosmologia clássicas.

Nesse sentido, ganha relevância o exercício do presente texto, o de devolver voz a dois cientistas brasileiros quanto ao sentido e à lógica de seu próprio percurso em ciência, o que é perseguido por Rocha e Silva e Freire-Maia fora dos campos específicos da farmacologia/ fisiologia e da genética, respectivamente.

Outra linha de força central da obra de Feyerabend é valorizar a contraindução como caminho privilegiado para o avanço da ciência. A esse respeito, o autor vai além de Karl Popper, crítico feroz do raciocínio indutivo ${ }^{4}$, posicionando-se antes como alguém que pretende virar de cabeça para baixo o raciocínio indutivo segundo perspectiva externalista, 
ou seja, com base em crítica de fora da ciência sob exame, e não em suas possíveis inconsistências internas. ${ }^{5}$ Tal posição o aproxima de outro filósofo da ciência, Thomas Kuhn, a quem credita explicitamente (Feyerabend, 1978, p.37) seu débito intelectual quanto à crítica ao indutivismo e à busca obsessiva da consistência dos achados empíricos com o conhecimento acumulado, como mecanismos reprodutores da ciência 'normal' e obstáculo às revoluções científicas - para utilizar a terminologia cara a Kuhn $\left(1971^{6}\right)$.

Outro aspecto fundamental da obra de Kuhn integralmente endossado por Feyerabend é a crítica ao conceito de fato em si, com argumentação em prol de sua concepção como algo necessariamente construído. Essa defesa, por parte de Feyerabend, do relativismo em ciência e filosofia, se torna mais enfática na edição de 1993. A defesa do caráter não apriorístico e da impureza do fato conduz Feyerabend a dois desdobramentos, a defesa algo tímida para autor tão veemente - da utilização de hipóteses ad hoc (formuladas $a$ posteriori e não a priori da verificação empírica) e a proposição de algo como um continuum entre observação e formulação de hipóteses, destituindo essa relação de qualquer precedência, seja ela de cunho temporal ou hierárquico.

O livro de Feyerabend termina com profunda crítica à epistemologia de Popper, além da defesa apaixonada do relativismo em filosofia, que ele considera desdobramento equivocado do empirismo reducionista, sobrando algumas farpas para seu fraterno amigo Lakatos, de seu ponto de vista de pensador mais flexível e plural do que Popper, mas, ainda assim, autor aquém da posição crítica de Feyerabend, ao conservar alguns dos fundamentos da epistemologia clássica, como na proposição de que a ciência se desenvolveria não exatamente por meio de conjecturas e refutações, como em Popper, mas balizada pelo que Lakatos denomina 'programas de investigação científica'. Munido de profundo sarcasmo, considera Lakatos criptoanarquista, alguém que algum dia irá se 'redimir' e abraçar de corpo inteiro o credo, ou anticredo, feyerabendiano, tese que retoma em sua correspondência com o próprio Lakatos (Motterlini, 1999).

Essa breve incursão pela vida e obra de Feyerabend não faz jus à diversidade de sua curiosidade intelectual e aos bizarros episódios que caracterizam sua biografia e correspondência, mas, enfim, sigamos adiante.

\section{Ideias fora do lugar: Rocha e Silva e a metodologia científica}

O livro em que Rocha e Silva critica, de forma muitas vezes confusa, o método científico procura desdobrar o conselho que lhe foi dado por seu então supervisor Max Bergman, pesquisador do Instituto Rockefeller, onde o autor estagiou na década de 1940: "De agora em diante, você deverá tentar os mais loucos pensamentos, isto é, as coisas mais malucas, para poder abrir caminho ou alguma brecha por onde prosseguir" (Mazzotti, 2007). Muito provavelmente o livro de Rocha e Silva (1965) teria caído no esquecimento, após décadas em que estudos no campo da filosofia, sociologia e história da ciência no Brasil amadureceram e se sofisticaram, caso não tivesse motivado longa correspondência com o educador Anísio Teixeira (1900-1971), compilada em livro reeditado em 2007 pela editora da Universidade Federal do Rio de Janeiro, no contexto da reedição das obras completas do educador (Teixeira, Rocha e Silva, 2007). 
Diante do ataque impiedoso que Rocha e Silva move contra o método científico e que se estende, de forma pouco organizada, para a ciência da época em que ambos viveram, Teixeira procura sustentar a validade do método científico e da ciência, contra críticas de Rocha e Silva em sua obra Lógica da invenção, que considera injustificadas e pouco embasadas filosoficamente (Teixeira, Rocha e Silva, 2007). O debate que travam por correspondência tem pontos altos e baixos, estes últimos quando a correspondência se transforma numa espécie de diálogo 'entre surdos' ou monólogo a dois, pois réplicas e tréplicas guardam escassas relações entre si, e cada um dos interlocutores argumenta segundo perspectivas incomensuráveis entre si. Ou seja, as perspectivas não operam em um mesmo solo epistemológico e, portanto, não podem ser comparadas, seja para as cotejar ou contrastar. ${ }^{7}$ Mas, a despeito das profundas discordâncias e de interações pouco proveitosas em muitas passagens, a correspondência entre Rocha e Silva e Anísio Teixeira se mantém, invariavelmente, respeitosa e cordial.

A confusão conceitual em que o diálogo se perde inúmeras vezes se deve, a meu ver, a diferentes razões, que provêm do fato de Rocha e Silva e Teixeira ancorarem seus pontos de vista, respectivamente, nas ciências naturais e nas ciências sociais e humanidades, tendo ambos uma compreensão deficiente dos campos em que o outro interlocutor se move - ao menos em tese, já que Rocha e Silva incursiona pelos mais variados tópicos e os combina de forma pouco usual. Especialmente, deve-se a uma série de equívocos conceituais, por parte de Rocha e Silva, na interpretação das recentes conquistas da ciência em campos que não lhe eram familiares, como a física.

Os zigue-zagues conceituais de Rocha e Silva pareceram a Mazzotti (2007, p.24, nota 15), responsável pela Apresentação do livro que compila a correspondência de Rocha e Silva e Teixeira, uma indevida transposição de conceitos de um campo do conhecimento a outro, nos moldes das críticas que Sokal e Bricmont (1997) tecem à utilização de conceitos científicos por parte dos filósofos pós-estruturalistas franceses. Sem entrar no mérito da famosa polêmica - iniciada com a publicação de um pastiche dos conceitos pós-estruturalistas na revista Social Text, entre Sokal e diversos intelectuais, especialmente franceses, seguida de inúmeras réplicas e tréplicas ${ }^{8}-$, parece residir aí uma pista interessante, ainda que parcial, para compreender os equívocos conceituais de Rocha e Silva, que Teixeira rebate com uma exposição bastante bem fundamentada da filosofia pragmática do filósofo e pedagogo norte-americano John Dewey (1859-1952), que fecha o volume em que se encontra a correspondência (Teixeira, Rocha e Silva, 2007, p.89-118).

Em primeiro lugar, cabe ver a tentativa de Rocha e Silva como esforço pioneiro de sistematizar a reflexão sobre a ciência em um país, à época, 1965, praticamente sem nenhuma tradição no campo da filosofia, história ou sociologia da ciência. Ciências no Brasil, obra em dois volumes organizada pelo educador e sociólogo Fernando de Azevedo, que data do início da década de 1950 e foi reeditada na década de 1990 pela editora da Universidade Federal do Rio de Janeiro, é claramente exceção à regra da quase absoluta ausência de textos de qualidade na área (Azevedo, 1994). A obra de Azevedo basicamente compila monografias redigidas por cientistas de cada área específica, sem a organicidade e a abrangência de documentação de obras posteriores como, por exemplo, a de Motoyama (2004). Da mesma forma, as publicações mais bem fundamentadas no campo da filosofia 
da ciência, em suas vertentes francófona (Machado, 1982) e anglo-germânica (Oliva, 1999), datam das últimas duas décadas do século XX.

Utilizando o conceito originalmente cunhado por Roberto Schwarz (1981), com finalidade algo diversa da original, acerca das 'ideias fora do lugar', a tentativa de Rocha e Silva soa não exatamente como a transposição de conceitos formulados em uma dada configuração social - em ambos os casos, seja a do livro de Schwarz ou a que contextualiza este artigo, a matriz é europeia -, para outra totalmente diversa, que serve de moldura à escrita ficcional - no caso de Schwarz, a transposição de conceitos europeus para o Brasil escravista e reacionário da época em que Machado de Assis redigiu seus primeiros romances -, mas como a transposição de conceitos das ciências europeias de vanguarda para a atmosfera brasileira, em que a reflexão sistemática sobre a filosofia da ciência era rarefeita e o mais das vezes ausente. Uma segunda translação conceitual confusa parece decorrente de as reflexões partirem de um cientista treinado em área determinada do conhecimento, a biomédica, e serem estendidas para outras áreas, como na utilização equivocada de conceitos da física. Ainda que em outro sentido, mostra-se válida a assertiva de Schwarz (p.24): "Ao longo de sua reprodução social, o Brasil põe e repõe ideias europeias, sempre em sentido impróprio".

Ao contrário de Feyerabend, que lastreia suas reflexões em exemplos extraídos da física e cosmologia clássicas, Rocha e Silva se apropria de forma pouco ordenada das formulações da ciência de sua época, primeiras décadas do século XX. Naquele momento, mesmo para os especialistas, pairavam dúvidas substanciais, algumas delas relevantes até hoje, acerca dos desdobramentos conceituais da revolução no campo da física empreendida por Einstein, quanto ao que Marcelo Gleiser (1997) denomina 'o mundo do muito veloz', a partir da teoria da relatividade especial e da física quântica, 'o mundo do muito pequeno', segundo Gleiser. Sem a sólida formação conceitual e matemática de autores que lhe são posteriores, como o físico e pensador Murray Gell-Mann (1994), Rocha e Silva utiliza de forma simplista conceitos oriundos da física quântica e os transpõe inadvertidamente para o que GellMann denomina "o mundo quase clássico" da física que perpassa nosso cotidiano - que não é nem muito veloz, nos moldes da física relativista, nem muito pequeno, nos termos que definem o universo quântico - e que obedecem, com grau de aproximação bastante aceitável, às leis da física clássica formulada por Isaac Newton. ${ }^{9}$

Um exemplo do imbróglio conceitual em que incorre Rocha e Silva pode ser extraído de uma de suas cartas a Anísio Teixeira, em que conceitos de física quântica e da psicanálise são misturados de forma despropositada:

\footnotetext{
O valor maior da concepção 'psicofísica' de Bohr [Niels Bohr, físico dinamarquês] reside em atacar o problema das inter-relações do id com o ego, como mundos de entidades complementares que representam um todo, da mesma maneira que em física quântica o universo dos fenômenos forma um todo com o universo dos aparelhos de medida, embora as relações entre um e outro sejam aquelas da indeterminação quântica ou da onda de probabilidade de De Broglie e Schrödinger (Teixeira, Rocha e Silva, 2007, p.35; grifos do original).
}

Em suma, é possível compreender o esforço de Rocha e Silva como uma tentativa malsucedida de fundamentar uma crítica filosófica ao método científico, por parte de um 
cientista da área biomédica que tenta, de forma pouco acurada, integrar as diferentes ciências e modalidades de conhecimento que emergem no início do século XX, como a física quântica e a psicanálise, sem o necessário conhecimento aprofundado de ambas, em um contexto - o brasileiro - absolutamente carente de reflexões sistemáticas em filosofia da ciência.

O conselho de Bergman, que motiva a redação do livro de Rocha e Silva - "Você deverá tentar os mais loucos pensamentos, isto é, as coisas mais malucas, para poder abrir caminho ou alguma brecha por onde prosseguir" - soaria como música aos ouvidos de Feyerabend - alusão não gratuita, pois além da formação em filosofia, ciências sociais, história e física, o autor era profundo conhecedor de música (Motterlini, 1999) -, mas acaba, em Rocha e Silva, por se perder em equívocos conceituais básicos, que comprometem a argumentação daquele que poderia ter sido um precursor no Brasil das ideias do autor de a: Contra o método.

No entanto, compreender esses equívocos como fruto da falta de conhecimento sistemático por parte de um cientista nos parece visão simplista da questão. Feyerabend, assim como seu alvo predileto, o filósofo da ciência austríaco Karl Raimund Popper (19021994), é herdeiro da sólida tradição filosófica austro-germânica. Ainda que Feyerabend e Popper interpretem a história da ciência, sobretudo a da física, de forma absolutamente distinta e com frequência oposta, ambos conhecem a fundo o objeto de suas reflexões, do ponto de vista tanto da filosofia como da ciência. Ambos estão inseridos, de forma antitética, na mesma tradição, com exemplos ilustres na física como na filosofia. Popper e Feyerabend são herdeiros, ainda que em contraposição - entre si ou ao cânone do positivismo lógico no estrito senso -, das reflexões do Círculo de Viena (der Wiener Kreis), grupo de filósofos, matemáticos e cientistas liderado por Moritz Schlick, que contou entre seus membros com algumas das mais brilhantes mentes do início do século $\mathrm{XX}$, fossem aderentes, como os filósofos Rudolf Carnap e Herbert Feigel, ou dissidentes, como o lógico Kurt Goedel (Goldstein, 2005).

Já Rocha e Silva é, antes de tudo, autodidata no campo pelo qual incursiona, a filosofia da ciência, tendo basicamente formação em farmacologia e fisiologia, mas não em outros campos da ciência, e com certeza não em filosofia. Além disso, está inserido em contexto no qual a reflexão sobre esses temas específicos não constitui de forma alguma um sistema, no sentido que o crítico literário Antonio Candido (1981, p.23) atribui ao conceito de sistema literário: "um sistema de obras ligadas por denominadores comuns, que permitem reconhecer as notas dominantes duma fase. Estes denominadores são, além das características internas (língua, temas, imagens), certos elementos de natureza social e psíquica .... que se manifestam historicamente e fazem da literatura aspecto orgânico da civilização". Transpondo esse conceito para a área da reflexão sobre a ciência, não é difícil constatar a absoluta inorganicidade intelectual do Brasil, sob esse aspecto, na época em que Rocha e Silva redigiu seu livro, uma iniciativa de cunho absolutamente individual, sem o respaldo de seus pares e de tradição acadêmica nesse campo específico. Não por acaso, Anísio Teixeira, que havia estudado em detalhe a filosofia da educação de Dewey nos Estados Unidos, se mostra bastante mais sistemático do que Rocha e Silva e aponta para as flagrantes inconsistências do pensamento desse protofeyerabendiano que, aparentemente, jamais 
conheceu a verdadeira fonte de inspiração de seu ataque ao método científico, em prol dos "mais loucos pensamentos".

\section{Delimitação de competências e parcimônia: Freire-Maia e sua visão sobre o diálogo entre ciência, arte e religião}

Freire-Maia era oito anos mais jovem do que Rocha e Silva, mas seus escritos aqui analisados são da sua maturidade, uma espécie de culminação de longa e bem-sucedida carreira na área da genética. A despeito de confessadamente não nutrir nenhuma pretensão a se tornar historiador ou filósofo da ciência no sentido sistemático/profissional - o que, aliás, explicita em sua obra póstuma (Freire-Maia, 2008) -, seus conhecimentos sobre as diversas áreas da ciência e de algumas correntes da filosofia são bastante amplos e, sob alguns aspectos, aprofundados.

Embora, assim como Rocha e Silva, até onde é de meu conhecimento, não cite em suas obras Feyerabend, compartilha com ele algumas preocupações, embora em tom nada radical; muito ao contrário, Freire-Maia é antes de tudo um homem cordial e ponderado em seus escritos.

Ainda que em clave distinta, três pontos centrais das reflexões de Feyerabend perpassam as ideias de Freire-Maia sobre ciência. Ambos não creem na unidade das diferentes ciências - programa explícito dos membros fundadores do Círculo de Viena, que chegaram a organizar na reedição, em solo norte-americano, dos debates do Círculo original, uma Enciclopédia das Ciências Unificadas (ver nota 3) -, nem na viabilidade de um método nos moldes do programa popperiano de fundamentar O Método Científico (em maiúsculas), objeto das críticas mais ácidas de Feyerabend. Em oposição a ele, porém, Freire-Maia aposta em interessante combinação de fundamentação genérica da ciência na lógica, seguindo aí, basicamente, correntes contemporâneas como a lógica paraconsistente do pensador brasileiro Newton da Costa, e uma espécie de mosaico de métodos específicos, particulares a cada ciência, aprendidos nos livros e artigos científicos, mas antes de tudo na relação tutorial de mestre e discípulo.

Em outra vertente, Freire-Maia se aproxima da crítica feyerabendiana, mas outra vez oferece resposta substancialmente distinta. Como Feyerabend, reconhece a dívida da ciência com uma variedade de saberes de diversa extração, como a música, a literatura e as artes plásticas, mas, em vez de tudo combinar num fluxo de pensamentos ou abolir as especificidades dos respectivos territórios, segundo a fórmula do "anything goes", inspira-o clara preocupação em demarcar territórios de cada saber, tornando a ciência uma aventura multidisciplinar, mas certamente não uma confluência dadaísta de propostas as mais diversas, como em Feyerabend. Embora não tenha tido acesso a detalhes biográficos de Freire-Maia, autor sobremaneira discreto, que escreve sempre em tom neutro e impessoal, parece-me que sua preocupação central é demarcar as fronteiras entre ciência e religião que parece professar, embora sem indicações claras nas obras consultadas. Sua posição quanto a esse aspecto lembra muito a de Stephen Jay Gould (2002), embora também não o cite quanto a essa questão específica, que em Rocks of ages procura delimitar os espaços de atuação da ciência e da fé a partir de uma discussão acerca da fundamentação da moral. 
Nesse caso específico, Freire-Maia e Gould se opõem de forma frontal à vertente basicamente calcada na biologia evolucionista, ainda embrionária enquanto ambos estavam vivos, mas hoje bastante difundida pelos propositores de uma ciência antirreligiosa. É muito provável que Gould - e talvez Freire-Maia, embora não haja nenhuma indicação clara disso - tenha lido o livro de Dennett, publicado originalmente em 1995 e intitulado Darwin's dangerous idea: evolution and the meaning of life, cuja segunda parte contempla uma tentativa de fundamentação da moral em bases que poderíamos denominar ultradarwinianas, pois combinam conceitos originais de Darwin com outros que o autor e o biólogo Richard Dawkins julgam representar desdobramentos das ideias de Darwin (Dennett, 1996). Como o livro inclui, em sua primeira parte, ácido e irônico ataque a Gould, provavelmente este o leu, mas teve a elegância de refutar em Rocks of ages, originalmente publicado em 1999, os argumentos de Dennett, sem menção aos ataques a ele desferidos.

Os ataques frontais de Dawkins e Dennett à religião e à fé são posteriores ao falecimento de Gould, em 2002, e Freire-Maia, em 2003, tendo sido ambos publicados em 2006 - The God delusion e Breaking the spell, respectivamente. Muito provavelmente os dois livros desagradariam ao discreto Freire-Maia e estão em frontal oposição às concepções de Gould acerca de ciência e religião. A provável reação do iconoclasta Feyerabend a ambas as obras deveria ser de júbilo, misturada ao sarcasmo habitual, em se tratando de mais um ataque à ortodoxia, embora seja difícil prever sua reação à emergência de uma nova ortodoxia aquela que aqui denominamos ultradarwiniana, mas que os próprios autores julgam ser o darwinismo puro, do que, pessoalmente, discordo.

Num terceiro e último ponto, encontramos ecos de Feyerabend em Freire-Maia - embora, ainda dessa feita, com desdobramentos distintos - na valorização da intuição e da emergência surpreendente de ideias inusitadas. Para Feyerabend, constitui profissão de fé um martelo, como o que caçaria as bruxas - demolir o espantalho do método. Freire-Maia, por seu turno, valoriza muito os episódios de intuição criativa, aos quais atribui algumas de suas ideias mais fundamentais, mas debita tais ideias emergentes na conta do mistério e do inusitado que nos cerca, habite ele o coração dos homens ou os confins do universo. Trata essas iluminações como episódios relevantes de sua vida pessoal. Convive, entretanto, de forma muito serena com a ideia de que muitas coisas escapam a nossa perquirição, seja por que caminho for, e mais ainda à perquirição específica da ciência, a qual enxerga como estratégia do conhecimento de contornos claramente delimitados, e não utiliza tais momentos em contraposição ao método científico tradicional, como Feyerabend, mas antes como seu complemento natural.

\section{Considerações finais}

Ainda que não mencionado explicitamente pelos dois cientistas brasileiros aqui analisados - Maurício Rocha e Silva e Newton Freire-Maia -, Paul Feyerabend parece involuntariamente inspirar as diatribes do primeiro contra o método científico e inspirar, a contrapelo, as respostas do segundo aos grandes dilemas da ciência contemporânea. Perpassa o pensamento dos três autores uma visão crítica da validade universal do método científico, embora oriunda de posições distintas. No caso de Feyerabend, trata-se do fulcro mesmo de seu 
pensamento como filósofo da ciência. No de Rocha e Silva, trata-se do eixo da incursão eventual e pouco feliz de um renomado fisiologista e farmacologista pela seara da filosofia da ciência. Finalmente, quanto a Freire Maia, trata-se de questão relevante, mas não central, para sua reflexão sobre a ciência e o método, sobremaneira eclética, aliás, como assinalado pelo próprio autor.

Cabe observar que se Rocha e Silva e Freire Maia estivessem vivos talvez negassem qualquer relação com o filósofo austríaco, ainda que implícita, nos moldes do presente artigo. Não seria demais, porém, imaginar o espírito deste último com um sorriso zombeteiro no canto dos lábios, constatando em que terra estranha suas ideias foram parar - neste Brasil em que a ciência então se consolidava e a reflexão sobre ela emergia, país que jamais visitou em sua errância sem descanso pelo mundo, mas que talvez lhe aprouvesse, ao menos no que compartilhamos com ele de irreverência.

\section{NOTAS}

${ }^{1}$ Nesta e nas demais citações de textos em outros idiomas, a tradução é livre.

${ }^{2}$ A análise da obra de Spinoza em si extrapola em muito o escopo deste artigo e, acima de tudo, nossa expertise. Ver interessante desdobramento de sua crítica ao dualismo corpo-mente cartesiano no contexto da moderna neurociência em Damasio, 2003 e sua complexa inter-relação com a tradição judaica e a filosofia da época em Goldstein, 2006.

${ }^{3} \mathrm{O}$ debate acerca da validade e consistência de um dado cânone cultural amplia-se progressivamente nas últimas décadas do século XX, com a valorização das culturas não ocidentais e com os debates sobre a relevância da contribuição de minorias, definidas segundo gênero, raça/etnia, identidade sexual, entre outros aspectos, e habitualmente subalternizadas pelo pensamento hegemônico. Em resposta ao que percebe como descaracterização do cânone literário, o crítico Harold Bloom (1995) empreende apaixonada defesa do que denomina "o cânone ocidental".

${ }^{4}$ A esse respeito ver, por exemplo, Oliva, 1999.

${ }^{5}$ Ver a excelente discussão sobre internalismo e externalismo em filosofia e sociologia da ciência em Labinger, Collins, 2001.

${ }^{6}$ Cabe observar que a edição aqui mencionada da obra de Kuhn é parte integral da Enciclopédia da Ciência Unificada, editada pelos líderes intelectuais do Círculo de Viena, então radicados nos EUA. A despeito de esposarem teses absolutamente opostas às de Kuhn, os editores da Enciclopédia tiveram a largueza de espírito de editar e disseminar a obra de um de seus críticos mais ferrenhos. Numa perspectiva distinta, Gaeta (2005) vislumbra uma convergência entre algumas das formulações de Rudolf Carnap (um dos editores da Enciclopédia), e Thomas Kuhn.

${ }^{7}$ A incomensurabilidade constitui conceito caro a Feyerabend (1978), que vê, nas diversas tentativas de comparação e contraste de visões distintas em prol de uma síntese ou julgamento de valor de qual seria mais ou menos acurada, um ato deliberado de reducionismo e mistificação (Motterlini, 1999).

8 Ver http://en.wikipedia.org/wiki/Sokal_affair.

${ }^{9}$ Um dos mais argutos autores no campo da física quântica, o austríaco Erwin Schrödinger mostra, por meio de experimento imaginário que se tornou clássico, habitualmente denominado 'o gato de Schroedinger', os paradoxos que podem emergir da interação entre as leis da física quântica e a experiência cotidiana. O experimento e seus desdobramentos são resumidos em verbete específico da Wikipedia (http://en.wikipedia.org/wiki/Schrodinger_cat) e discutidos em detalhe no referido livro de Gell-Mann (1994). 


\section{REFERÊNCIAS}

AZEVEDO, Fernando.

As ciências no Brasil. 2 v. Rio de Janeiro: Editora da UFRJ. 1994.

BLOOM, Harold.

The Western canon: the books and school of the ages. Nova York: Riverhead Trade. 1995.

CANDIDO, Antonio.

Formação da literatura brasileira. São Paulo: Itatiaia. 1981.

DAMÁSIO, Antonio.

Looking for Spinoza: joy, sorrow, and the feeling brain. Nova York: Harvest. 2003.

DENNETT, Daniel C.

Darwin's dangerous idea: evolution and the meaning of life. Nova York: Touchstone. 1996.

FEYERABEND, Paul.

Against method: outline of an anarchistic theory of knowledge. Londres: Verso. 1978.

FREIRE-MAIA, Newton.

Verdades da ciência e outras verdades: a visão de um cientista. São Paulo: Editora Unesp;

Sociedade Brasileira de Genética. 2008.

FREIRE-MAIA, Newton.

A ciência por dentro. Petrópolis: Vozes. 2000.

GAETA, Rodolfo.

A filosofia da ciência hoje: a crítica da crítica e o retorno ao realismo. In: Regner, Anna Carolina; Rohden, Luiz (Ed.). A filosofia e a ciência redesenham horizontes. São Leopoldo: Editora Unisinos. p. 32-50. 2005.

GELL-MANN, Murray.

The quark and the jaguar: adventures in the simple and the complex. Nova York: W.H. Freeman and Company. 1994.

GLEISER, Marcelo.

A dança do universo. São Paulo: Companhia de Bolso. 1997.

GOLDSTEIN, Rebecca.

Betraying Spinoza: the renegade Jew who gave us modernity. Nova York: Schocken. 2006.

GOLDSTEIN, Rebecca.

Incompletness: the proof and paradox of Kurt Gödel. Nova York: W.W. Norton. 2005.

GOULD, Stephen Jay.

Rocks of ages: science and religion in the fullness of life. Reading: Vintage. 2002.
KUHN, Thomas.

The structure of scientific revolutions. Chicago: University of Chicago Press. (Foundations of the Unity of Science: Toward an International Encyclopedia of Unified Science, v.2). 1971.

LABINGER, Jay A.; COLLINS, Harry (Ed.).

The one culture?: a conversation about science. Chicago: University of Chicago Press. 2001.

LATOUR, Bruno; WOOLGAR, Steve.

Laboratory life: the construction of scientific facts. Princeton: Princeton University Press. 1986.

MACHADO, Roberto.

Ciência e saber: a trajetória da arqueologia de Foucault. Rio de Janeiro: Graal. 1982.

MAZZOTTI, Tarso B.

Apresentação. In: Teixeira, Anísio; Rocha e Silva, Maurício. Diálogo sobre ao lógica do conhecimento. Rio de Janeiro: Editora da UFRJ. 2007.

MOTOYAMA, Shozo (Org.).

Prelúdio para uma história: ciência e tecnologia no Brasil. São Paulo: Edusp; Fapesp. 2004.

MOTTERLINI, Matteo.

For and against method: Imre Lakatos and Paul Feyerabend. Chicago: University of Chicago Press. 1999.

OLIVA, Alberto.

Ciência e sociedade: do consenso à revolução. Porto Alegre: EdiPucRS. 1999.

ROCHA E SILVA, Maurício.

Lógica da invenção. Rio de Janeiro: Livraria São José. 1965.

SCHWARZ, Roberto.

Ao vencedor as batatas: forma literária e processo social nos inícios do romance brasileiro. São Paulo: Duas Cidades. 1981.

SOKAL, Alain; BRICMONT, Jean. Impostures intellectuels. Paris: Odile Jacob. 1997.

TEIXEIRA, Anísio; ROCHA E SILVA, Maurício. Diálogo sobre o conhecimento: correspondência entre Anísio Teixeira e Maurício Rocha e Silva. Rio de Janeiro: Editora da UFRJ. 2007. 